\title{
A practical method to determine the dynamic fracture strain for the nonlinear finite element analysis of structural crashworthiness in ship-ship collisions
}

\author{
Yeong Gook Ko ${ }^{\mathrm{a}}$, Sang Jin Kim ${ }^{\mathrm{b}}$, Jung Min Sohn ${ }^{\mathrm{c}}$ and Jeom Kee Paik ${ }^{\mathrm{a}, \mathrm{b}, \mathrm{d}^{*}}$
}

\author{
${ }^{a}$ Department of Naval Architecture and Ocean Engineering, Pusan National University, Busan \\ 46241, Korea \\ b The Korea Ship and Offshore Research Institute (The Lloyd's Register Foundation Research \\ Centre of Excellence), Pusan National University, Busan 46241, Korea \\ c Department of Naval Architecture and Marine Systems Engineering, Pukyoung National \\ University, Busan 48547, Korea \\ ${ }^{\mathrm{d}}$ Department of Mechanical Engineering, University College London, London WC1E 7JE, UK \\ * Corresponding author. J.K. Paik. Tel.: +82 51510 2429, Email address: jeompaik@ pusan.ac.kr
}

\begin{abstract}
Ship collision accidents continue to occur regardless of efforts to prevent them. Ship-ship collisions involve highly nonlinear characteristics associated with structural crashworthiness, including crushing and fracture as well as buckling and plastic collapse. When applying nonlinear finite element method simulations to solve these problems, a reliable value of critical fracture strain accounting for strain-rate effects due to collision speed must be implemented. This study aims to propose a practical method to estimate the dynamic fracture strain to be used for the structural crashworthiness analysis associated with ship-ship collisions using the nonlinear finite element method. For this purpose, the strain-rate characteristics in struck ship structures were investigated by nonlinear finite element method computations, in which the striking vessel was assigned various velocities from 0.5 to 20 knots in the range of practical ship speeds. Based on the computations, an empirical formula was developed to calculate the strain rate at a collision scenario with a given collision speed, allowing for a practical estimation of the dynamic fracture strain. The formula is validated by a comparison with experimental data.
\end{abstract}




\section{Keywords}

Ship-ship collision, structural crashworthiness, strain rate, dynamic fracture strain, nonlinear finite element analysis.

\section{Introduction}

Ships and offshore structures can be subjected to various types of accidents such as collisions, grounding, fire, and explosions. Collision as shown in Figure.1 is one of the most frequent types of accidents in shipping, and they may lead to serious consequences to personnel, assets and the environment. In particular, when an oil tanker is involved in collisions, serious marine pollution can occur by the release of crude oil and/or petroleum into the ocean (Tavakoli et al. 2012, Kim et al. 2015). To prevent such consequences, it is necessary to accurately simulate the structural crashworthiness of ships involved in the accident, including the impact strength and extent of damage. Many studies have been undertaken in the literature, and risk- and simulation-based design methods have been recommended to improve collision safety of ships (Paik and Chung 1999, Zheng et al. 2007, 2015, Khan and Das 2008, Samuelides et al. 2009, Ehlers et al. 2012, 2017, Tabri 2012, Haris and Amdahl 2012a, 2012b, Youssef et al. 2014, 2016, 2017, Faisal et al. 2016, Samuelides 2015, Faisal et al. 2016, Obisesan 2016, Zhang and Pedersen 2017, Ko et al. 2017, Paik et al. 2017a).

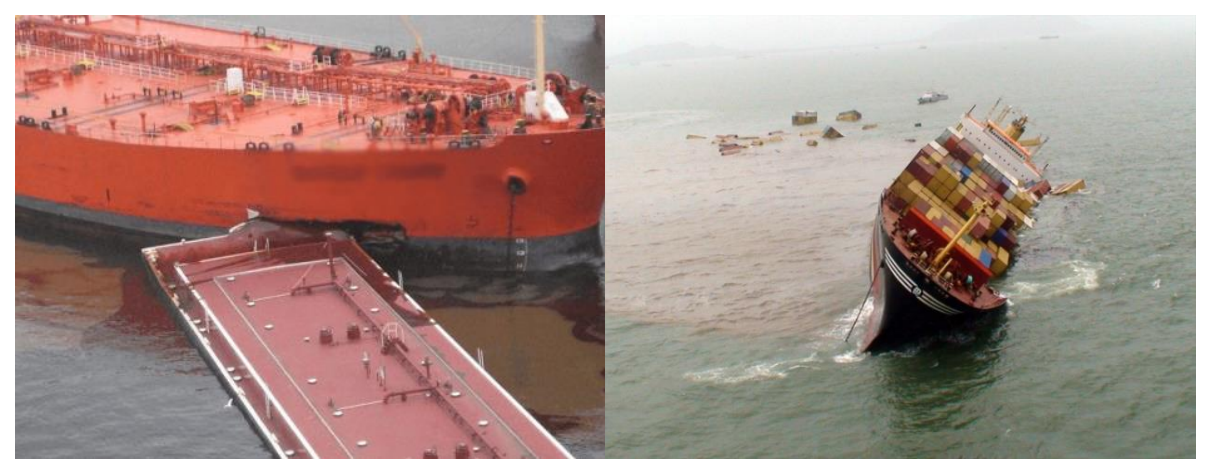

Figure 1. Ship collision accidents and marine pollution due to the collision.

To investigate the consequences of ship collisions, various methods such as analytical solutions, empirical formulas, experiments, and finite element (FE) analysis are available (DNV 2004, GL 2011, BV 
2013, Liu and Guedes Soares 2016). The nonlinear finite element method (NLFEM) in particular has been considered as a powerful and useful method for more refined computations of the structural crashworthiness in ship collisions.

A structural impact response without fracture can be obtained accurately by NLFEM with the actual material properties and boundary conditions (Liu and Guedes Soares 2016, Ko et al. 2017). However, it is difficult to predict the structural impact response with fracture because of the dynamic effect (e.g., dynamic fracture strain), among other factors. As such, it is important to apply an accurate dynamic fracture strain in the investigation of structural impact behavior involving fracture because fracture of the structure is inevitable in collision accidents.

In the current industry practice for ship-ship collision FE analysis, a dynamic fracture strain of 0.1 $(\mathrm{mm} / \mathrm{mm})$ obtained using the experiential approach and past experiences is often used (Paik and Chung 1999, Paik et al. 1999, Servis et al. 2002, Sajdak and Brown 2005, Jones 2006, Paik and Thayamballi 2007, Paik et al. 2009, Hughes and Paik 2013) when precise considerations of factors affecting the dynamic fracture strain are unavailable. Although this value is considered to be reasonable, a more accurate dynamic fracture strain that considers factors such as material properties, and collision speed needs to be defined.

The aim of this study is to develop a practical method to predict the strain rates and also to determine the dynamic fracture strain to be used for the nonlinear finite element analysis of structural crashworthiness in ship-ship collisions. The proposed method is validated by a comparison with experimental results.

\section{Parametric studies of nonlinear FEA with varying collision speed}

In nonlinear FEA of structural crashworthiness in collisions, the Cowper-Symonds equation (Cowper and Symonds 1957) is typically used to determine the dynamic yield strength with the static yield strength known (Jones 2012): 


$$
\sigma_{Y d}=\left[1+\left(\frac{\dot{\varepsilon}}{C}\right)^{1 / q}\right] \sigma_{Y}
$$

where $\sigma_{Y}$ is the static yield strength, $\sigma_{Y d}$ is the dynamic yield strength, and $\dot{\varepsilon}$ is the strain rate. $\mathrm{C}$ and $\mathrm{q}$ are the Cowper-Symonds coefficients. While the static yield strength $\sigma_{Y}$ is defined from the material properties, the strain rate in Equation (1) is implicitly defined in the nonlinear FEA depending on the collision speed, among other factors. The dynamic yield strength $\sigma_{Y d}$ can then be automatically defined in the nonlinear FEA.

On the other hand, the dynamic fracture strain should be directly defined by the analyst of the nonlinear FEA in advance. In fact, an inverse of the Cowper-Symonds equation as a function of the strain rate (Jones 2012, Paik et al. 2017b) is used to define the dynamic fracture strain as follows:

$$
\varepsilon_{f d}=\left[1+\left(\frac{\dot{\varepsilon}}{C}\right)^{1 / q}\right]^{-1} \varepsilon_{f}
$$

where $\varepsilon_{f}$ is the static fracture strain and $\varepsilon_{f d}$ is the dynamic fracture strain. $\dot{\varepsilon}, C$ and $q$ are defined in Equation (1). Upon using Equation (2) in the nonlinear FEA, however, one would not know the strain rate in advance, and thus it is difficult to define the dynamic fracture strain properly.

In this paper, a series of nonlinear finite element method computations are undertaken with varying the collision speed in association with the structural crashworthiness in ship-ship collisions in order to characterize the strain rates as a function of collision speed. The structural crashworthiness is computed by the ANSYS/LS-DYNA nonlinear finite element method tool which is an explicit code with MCOL program to consider the added mass and motion of ships while ship collision occurs (ANSYS/LS-DYNA 2016). Figure 2 illustrates the flowchart to investigate the strain rates of ship structures involved in collisions. Details of the procedure are described as follows:

1) Selection of ship-ship collision scenarios: Collision scenarios with different ship striking speeds are selected to investigate the strain rates depending on the collision speed. 
2) Nonlinear finite element analysis and characterization of strain rates: Strain rates at the impact area are examined by nonlinear structural analysis.

3) Derivation of an empirical formula for strain rates: An empirical formula is derived with the obtained strain rates at the impact area at the side shell of the struck ship.

In the present study, a very large crude oil carrier (VLCC) class double-hull oil tanker as indicated in Table 1 was selected in the parametric studies as the target struck ship, where ship speeds were varied to investigate the effects of striking ship's velocity. It is emphasized that the strain-rate characteristics may depend on the structural characteristics as well as the collision speed, among other factors. However, the insights and findings of the strain-rate characteristics obtained from the present parametric studies may be applied to ship-ship collision accidents in general.

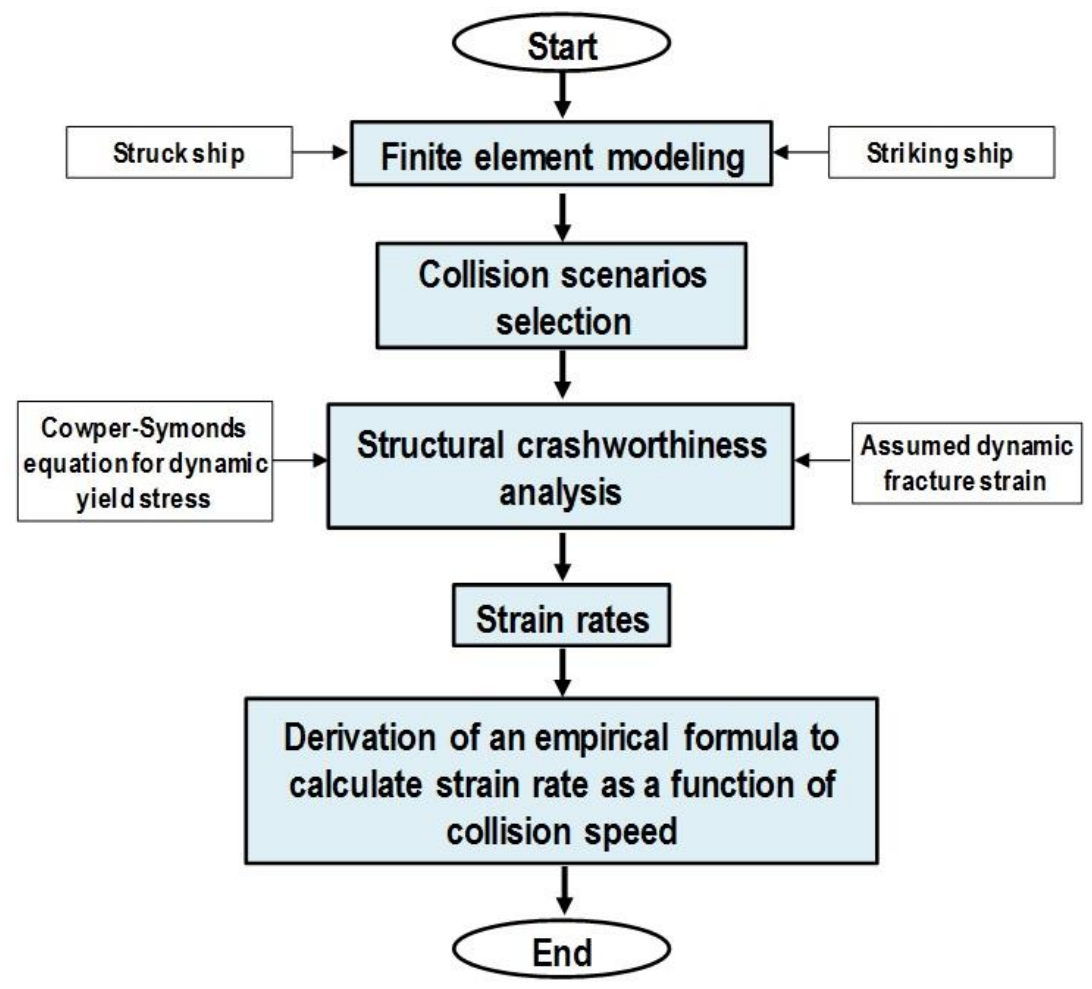

Figure 2. Flowchart of characterizing the strain rates as a function of the collision speed in the present parametric studies. 
Table 1. Principal dimensions of the struck VLCC vessel.

\begin{tabular}{|c|c|}
\hline Parameter & Dimension \\
\hline \hline Length over all $(\mathrm{m})$ & 318.2 \\
\hline \hline Length between perpendiculars $(\mathrm{m})$ & 309.3 \\
\hline Molded breadth $(\mathrm{m})$ & 60.0 \\
\hline Molded depth $(\mathrm{m})$ & 30.0 \\
\hline Molded draught $(\mathrm{m})$ & 21.6 \\
\hline Dead weight (ton) & 300,000 \\
\hline Block coefficient & 0.81 \\
\hline
\end{tabular}

\subsection{Selection of ship-ship collision scenarios}

Figure 3 presents the schematic of a ship-ship collision accident. In a ship collision, the key parameters affecting the structural crashworthiness are the striking ship's speed, the impact location, and the angle, among others. In the present study, the bow of the VLCC tanker in the ballast condition is considered to collide with the side structure of the VLCC tanker in the full load condition where the collision speed is varied, while the collision angle is fixed at $90^{\circ}$ and the collision location is in No.4 cargo tank of the struck ship, as shown in Figure 4. The operating speed of the struck ship is considered to be 2 knots. To investigate the characteristics of the structural crashworthiness due to dynamic fracture strain, two cases are studied at $\varepsilon_{f d}=0.1$ and 0.3 in association with Equation (2).

The collision scenarios selected for the parametric studies to investigate the strain rates are summarized as follows:

- Struck ship: VLCC class double-hull oil tanker in the full load condition

- Striking ship: VLCC class double-hull oil tanker in the ballast condition

- Operating speed of the struck ship: 2 knots

- Collision speed of the striking ship: $0.5,3,5,7,10,13,15,18$, and 20 knots

- Collision location: No. 4 cargo tank of the struck ship

- Collision angle: $90^{\circ}$

- Dynamic fracture strain: $0.1,0.3$ 


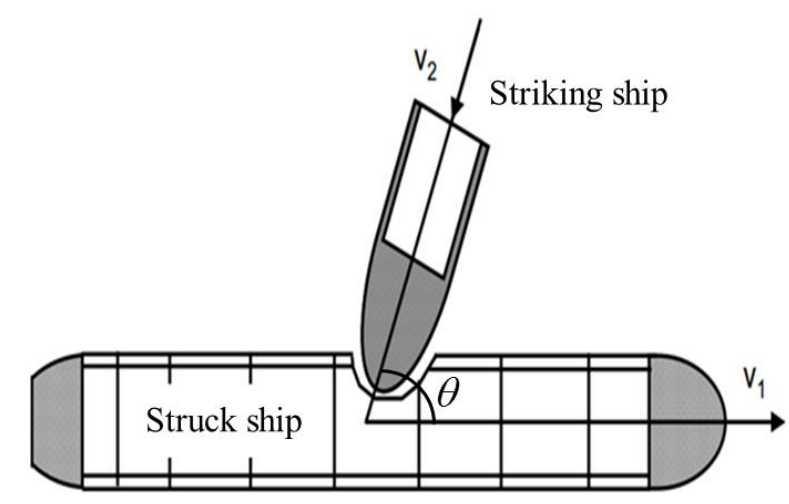

Figure 3. Schematic representation of ship-ship collision.

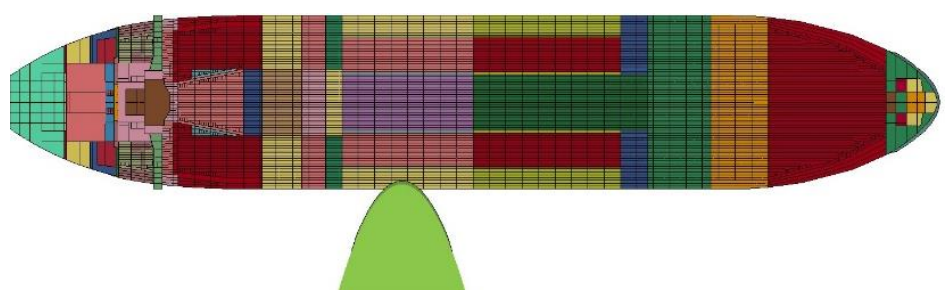

(a) Plan view

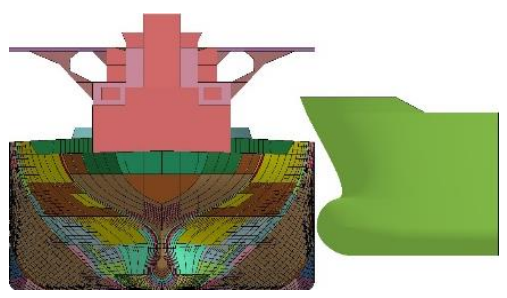

(b) Front view

Figure 4. Collision angle and location considered in the present parametric studies.

\subsection{Extent of the FEA}

For the extent of the analysis, an entire struck-ship is taken as shown in Figure 5, while only the bow structure of the striking ship is taken as shown in Figure 6. However, the center of mass and the full weight of the striking ship are considered in the analysis as shown in Figure 6. 


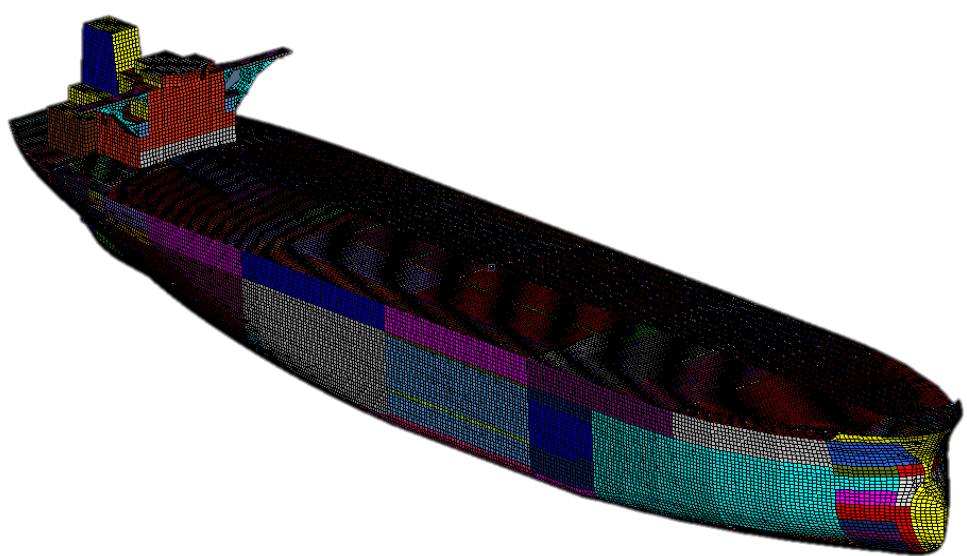

Figure 5. Extent of the FEA for the struck vessel.

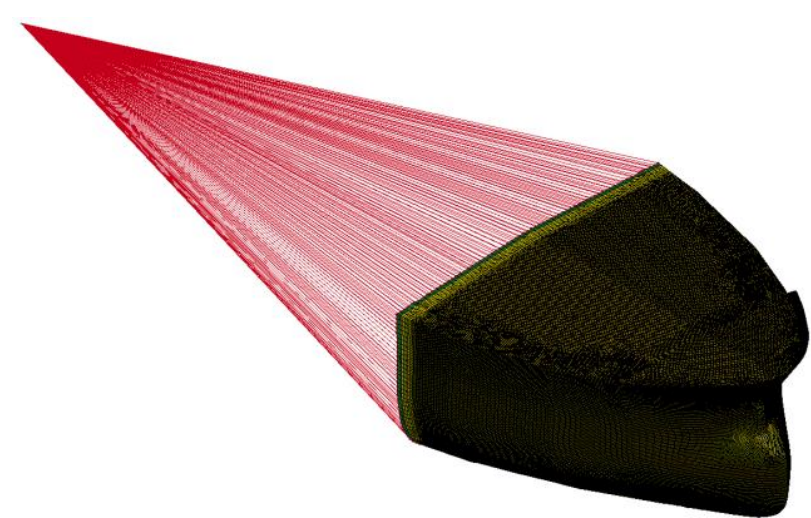

Figure 6. Extent of the FEA for the striking ship with the center of mass.

\subsection{Effect of deformable striking ship bow}

In the present study, the striking ship bow structures are modelled as a deformable body. The effects of a deformable striking-ship bow on the structural crashworthiness are studied in detail in Ko et al. (2017), concluding that they are small until inner hull is penetrated at a collision of $90 \mathrm{deg}$. between the striking and struck ships. However, after the inner hull is penetrated at the right collision angle or at different collision angles even before the inner hull is penetrated, the structural crashworthiness in shipship collisions with a deformable striking-ship bow is totally different from that with a rigid striking ship bow. This issue may become more significant when the collision location is around fuel tanks of a ship powered by liquefied natural gas or nuclear reactor. 


\subsection{Type of finite elements}

All of the structures in the struck ship, including plating, longitudinal girders and transverse frames are modelled using 4-node plate-shell elements, but no beam elements are used.

\subsection{Size of finite elements}

The aspect ratio of the plate element is almost unity. Finer meshes are applied in the area near the collision location, while coarse meshes are applied in the area far away from the collision location. The size of the coarse mesh is approximately $1,000 \mathrm{~mm}$ for plating. One plate element is used for the web of a support member such as stiffener, girder or frame. For T-type stiffeners, one plate element is used for each side of the flange although the aspect ratio may not be unity in this case.

The size of fine meshes needs to be determined to be able to describe the crushing behavior in collision. Convergence study is usually applied to determine the best size of fine meshes that can minimize the computational cost while achieving the resulting accuracy at a successful level. However, the convergence study also requires labor cost. Hughes and Paik (2013) therefore suggested a practical method to determine the best size of fine meshes without the convergence study.

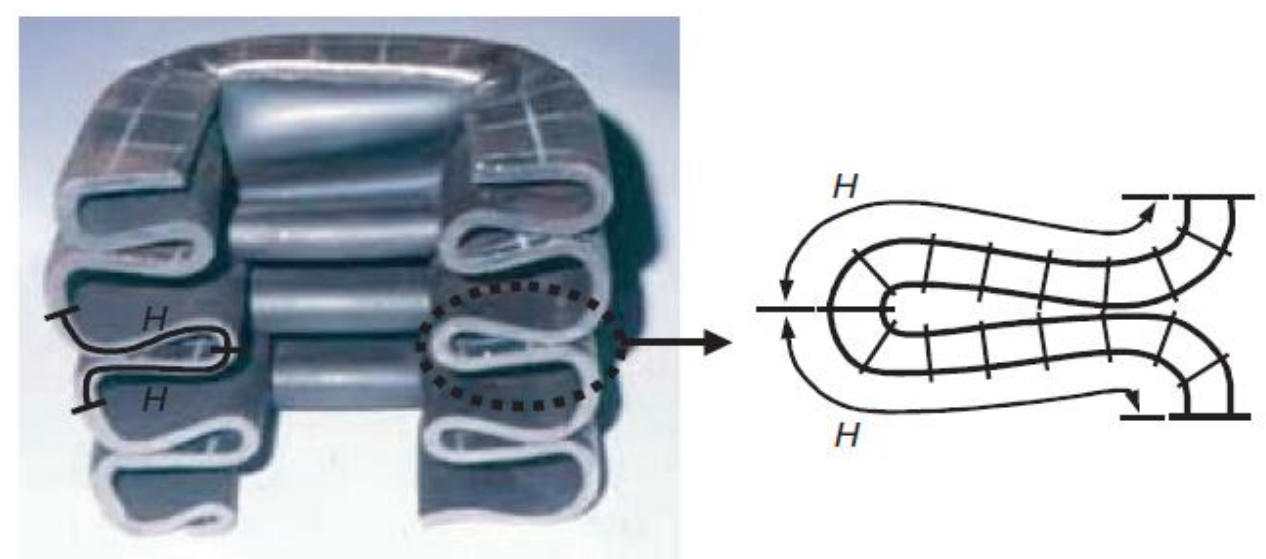

Figure 8. A thin-walled structure crushed under predominantly axial compression and cut at its midsection (Paik and Thayamballi 2003). 
Figure 8 shows the crushing test result of a thin-walled box-column under axial compressive loading (Paik and Thayamballi 2003). It is obvious from Figure 8 that at least 8 finite elements are needed to describe the crushing behavior for a half-folding length. Therefore, the size $s$ of one fine mesh should fulfil the following condition.

$$
s \leq \frac{H}{8}
$$

where $s$ is the element size, $H$ is the half-fold length which may be taken as $H=0.983 b^{\frac{2}{3}} t^{\frac{1}{3}}$ (Wierzbiki and Abramowicz 1983), $b$ is the plate breadth between support members (e.g., stiffeners, frames, stringers), and $t$ is the plate thickness. Equation (3) can then be rewritten as follows:

$$
s \leq \frac{H}{8}=0.1228 b^{\frac{2}{3}} t^{\frac{1}{3}}
$$

Table 2. The size of fine meshes determined using Equation (4).

\begin{tabular}{|l|c|c|c|c|}
\hline \multicolumn{1}{|c|}{ Area } & $\begin{array}{c}\text { Breadth of plate, } \\
b(\mathrm{~mm})\end{array}$ & $\begin{array}{c}\text { Plate thickness, } t \\
(\mathrm{~mm})\end{array}$ & $\begin{array}{c}\text { One half-fold } \\
\text { length, } H(\mathrm{~mm})\end{array}$ & $\begin{array}{c}\text { Element size, } s \\
(\mathrm{~mm})\end{array}$ \\
\hline \hline Frame space & 5690 & 18.5 & 828.61 & 103.68 \\
\hline Deck height & 6600 & 24 & 997.67 & 124.84 \\
\hline $\begin{array}{l}\text { Hull depth (except } \\
\text { double bottom }\end{array}$ & 20608 & 18.5 & 1954.20 & 244.52 \\
\hline
\end{tabular}

Applying Equation (4) gives the size of fine meshes as indicated in Table 2. It is obvious from Table 2 that the size of fine meshes is of course not identical for different members depending on the structural characteristics. In order to verify the method of Hughes and Paik (2013) or Equation (4), a convergence study was undertaken here. For simplicity, however, it is presumed in the present convergence study that the size of fine meshes is identical for all structural members near in the collision location. Figure 9 shows the results of the convergence study. It is surmised from Figure 9 that Equation (4) gives a reasonable guidance to determine the best size of mesh sizes. On the other hand, it is noted that the actual 
nonlinear FEA of the structural crashworthiness in the present parametric studies is performed with the size of fine meshes indicated in Table 2.

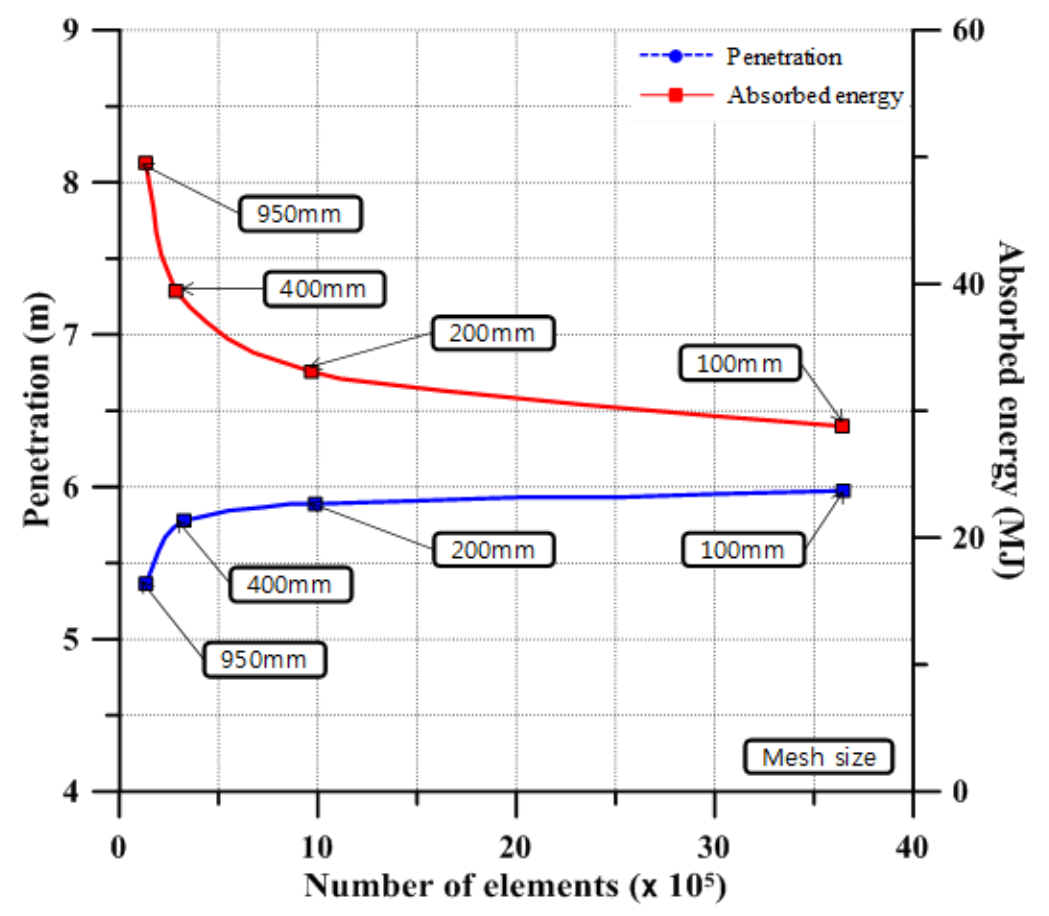

Figure 9. Results of the convergence study with the identical size of fine meshes.

\subsection{Material properties}

Plate members of the striking ship are made of mild steel (MS), and high-tensile steels (AH32 and 36) are used as materials for strength members, which are stiffeners and frames. Table 3 indicates the detailed material properties of the struck ship, with an elastic perfectly-plastic material model applied, without considering the strain-hardening effect where the material option of "Piecewise Linear Plasticity" was adopted considering the dynamic effects (Sajdak and Brown 2005, Paik 2007a, 2007b). The CowperSymonds coefficients in Equation (1) are defined as indicated in Table 3.

As mentioned earlier, the dynamic yield strength $\sigma_{Y d}$ is automatically defined in the nonlinear FEA from Equation (1) because the strain rate $\dot{\varepsilon}$ is computed in the nonlinear FEA and the static yield 
strength $\sigma_{Y}$ and the Cowper-Symonds coefficients $C$ and $q$ are defined in advance as indicated in Table 3. The dynamic fracture strain $\varepsilon_{f d}$ is assumed to be 0.1 or 0.3 in the present parametric studies.

Table 3. Material properties of the struck vessel (VLCC class double hull oil tanker).

\begin{tabular}{|c|c|c|c|}
\hline \multirow{2}{*}{ Material property } & \multirow{2}{*}{ Mild steel } & \multicolumn{2}{|c|}{ High-tensile steel } \\
\hline & & AH32 & AH36 \\
\hline Density, $\rho\left(\right.$ ton $\left./ \mathrm{m}^{3}\right)$ & 7.85 & 7.85 & 7.85 \\
\hline Young's modulus, E (MPa) & 205,800 & 205,800 & 205,800 \\
\hline Poisson's ratio, $v$ & 0.3 & 0.3 & 0.3 \\
\hline Yield stress, $\sigma_{Y}(\mathrm{MPa})$ & 235 & 315 & 315 \\
\hline \begin{tabular}{l|l} 
Cowper- & $C$ \\
\cline { 2 - 2 }
\end{tabular} & 40.4 & 3,200 & 3,200 \\
\hline $\begin{array}{l}\text { Symonds } \\
\text { coefficient }\end{array}$ & 5 & 5 & 5 \\
\hline
\end{tabular}

\subsection{Effect of surrounding water}

In a ship-ship collision on the ocean, neither the striking nor struck vessels are fixed in any direction, and they must be able to move naturally as a result of the collision. In addition, the effect of surrounding seawater associated with added mass on the ship's motion should be considered.

The free-body boundary condition (without displacement or rotational restrictions) of the ship was applied using the LS-DYNA/MCOL program, which calculated the actual ship motion considering the added mass after the collision (ANSYS/LS-DYNA 2016, Kuroiwa et al. 1995, Kuroiwa 1996, Kitamura 2000, Le Source et al. 2003). Figure 7 illustrates the LS-DYNA/MCOL model for collision simulation (Ferry et al. 2002). In MCOL simulations, the added masses in Eq. (3) were used in the surge, sway, and yaw directions to consider the effect of surrounding seawater (Ferry et al. 2002).

$$
a_{11}=c_{11} m_{2}, a_{22}=c_{22} m_{2}, a_{33}=c_{33} I_{2}
$$

where $a_{11}, a_{22}$, and $a_{33}$ are the added masses in the direction of surge, sway, and yaw motions, respectively, $c_{11}, c_{22}$, and $c_{33}$ are the coefficients of the added masses for each motion, $m_{2}$ is the mass of the struck vessel, and $I_{2}$ is the mass moment of inertia of the struck vessel. 


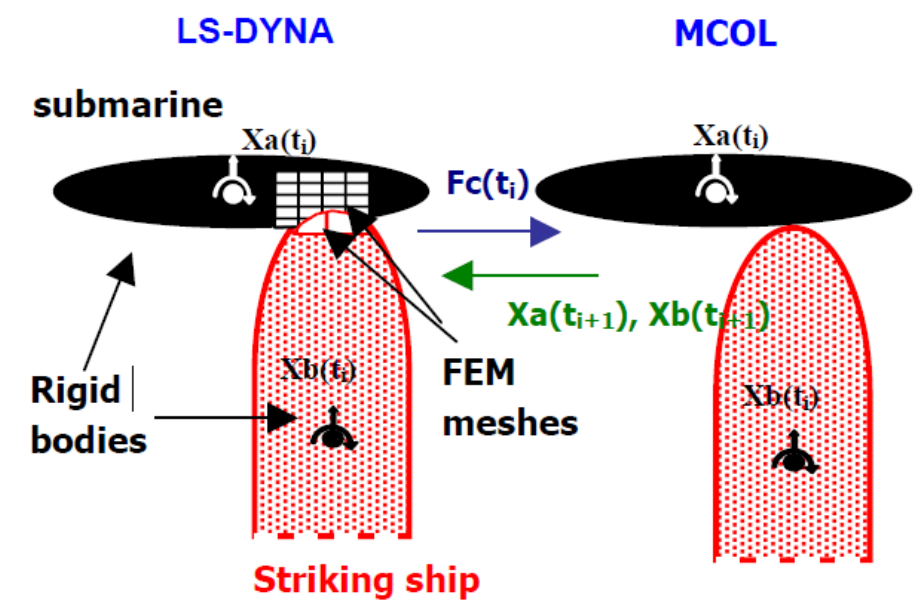

Figure 7. Boundary system in LS-DYNA/MCOL collision simulation (Ferry et al. 2002).

\subsection{Definition of strain rates}

The first fracture of a structure in a ship-ship collision usually occurs at the contact point where the striking ship runs into the struck ship. Thus, the first contact point (i.e., side shell of the struck ship) was monitored to investigate the time-dependent strain rate and strain depending on velocities, as shown in Figure 10.

In this study, the time-dependent strain of each collision scenario was observed at the side shell of the struck ship to convert to the strain rate, as the strain rate could not be directly obtained in ANSYS/LSDYNA. The strain rate was thus calculated using time-dependent strain as follows:

$$
\dot{\varepsilon}=\frac{\Delta \varepsilon}{\Delta t}
$$

where $\Delta \varepsilon$ is the increment of strain and $\Delta t$ is the increment of time. 


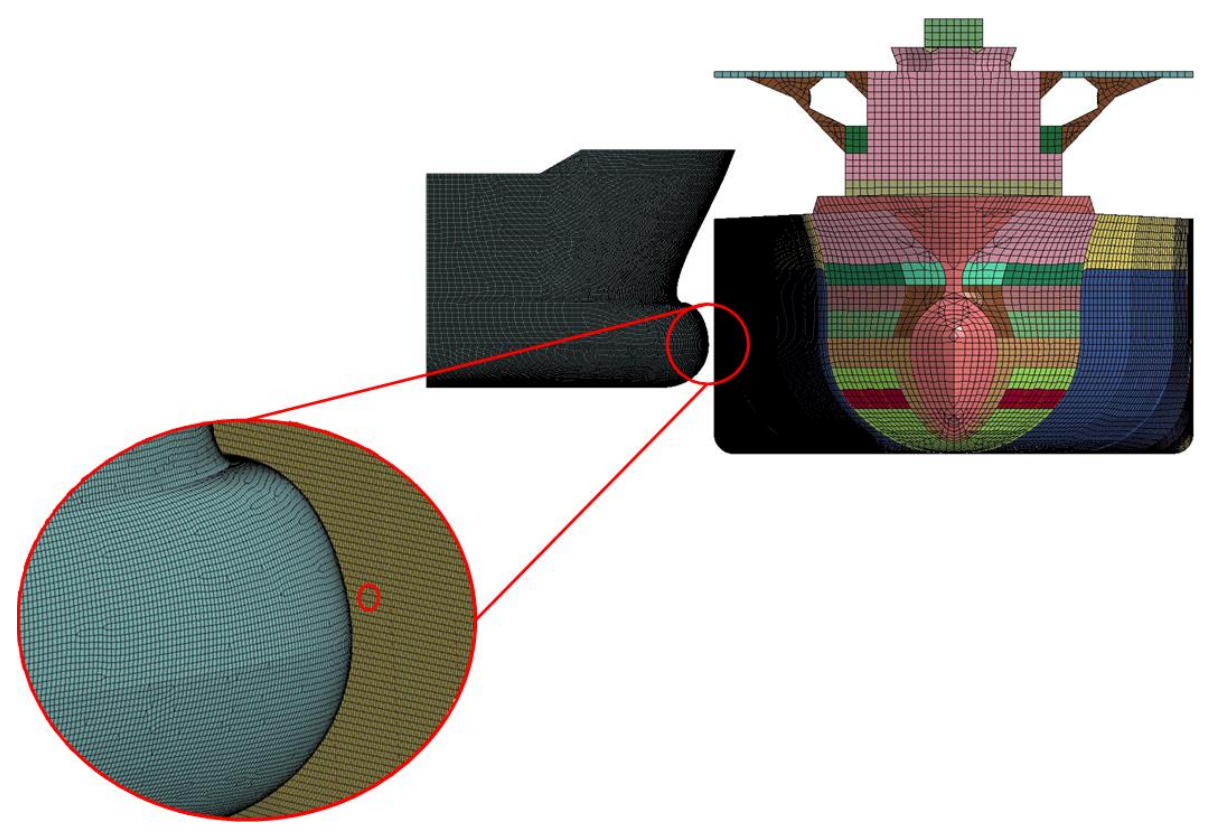

Figure 10. Monitoring elements at side shell of the struck ship for investigating strain.

\subsection{Computed results of strains and strain rates}

Figure 11 presents the computed results of strains with time at the side shell of the struck ship. It is interesting to say that the strain increases quickly in the beginning of collision with time, and the increase of strain tends to moderate as the striking ship bow further penetrates into the struck ship. The dynamic fracture strain value significantly affects the structural crashworthiness at high collision-speed, although the effect of it is negligible when the collision speed is slow.

The strain rates can be obtained from Equation (6). Figure 12 presents the computed strain-rates with time at the side shell of the struck ship, showing that it increases with time in the beginning of collision but it decreases with time in the later penetration process. It is also obvious from Figure 12 that the strain rate increases as the collision speed increases. Table 4 summarizes the maximum strain-rates at the side shell of the struck ship depending on the collision speed and dynamic fracture strain. 
Table 4. Maximum strain-rates as a function of collision speed and dynamic fracture strain.

\begin{tabular}{|c|c|c|}
\hline \multirow{2}{*}{ Collision velocity (knot) } & \multicolumn{2}{|c|}{ Maximum strain rate } \\
\cline { 2 - 3 } & $\varepsilon_{f d}=0.1$ & $\varepsilon_{f d}=0.3$ \\
\hline 0.0 & 0.000 & 0.000 \\
\hline 0.5 & 0.279 & 0.283 \\
\hline 3.0 & 3.460 & 3.454 \\
\hline 5.0 & 6.659 & 6.672 \\
\hline 7.0 & 9.612 & 9.615 \\
\hline 10.0 & 14.414 & 14.369 \\
\hline 12.0 & 17.738 & 17.751 \\
\hline 15.0 & 22.389 & 22.294 \\
\hline 18.0 & 26.829 & 26.841 \\
\hline 20.0 & 30.089 & 30.103 \\
\hline
\end{tabular}

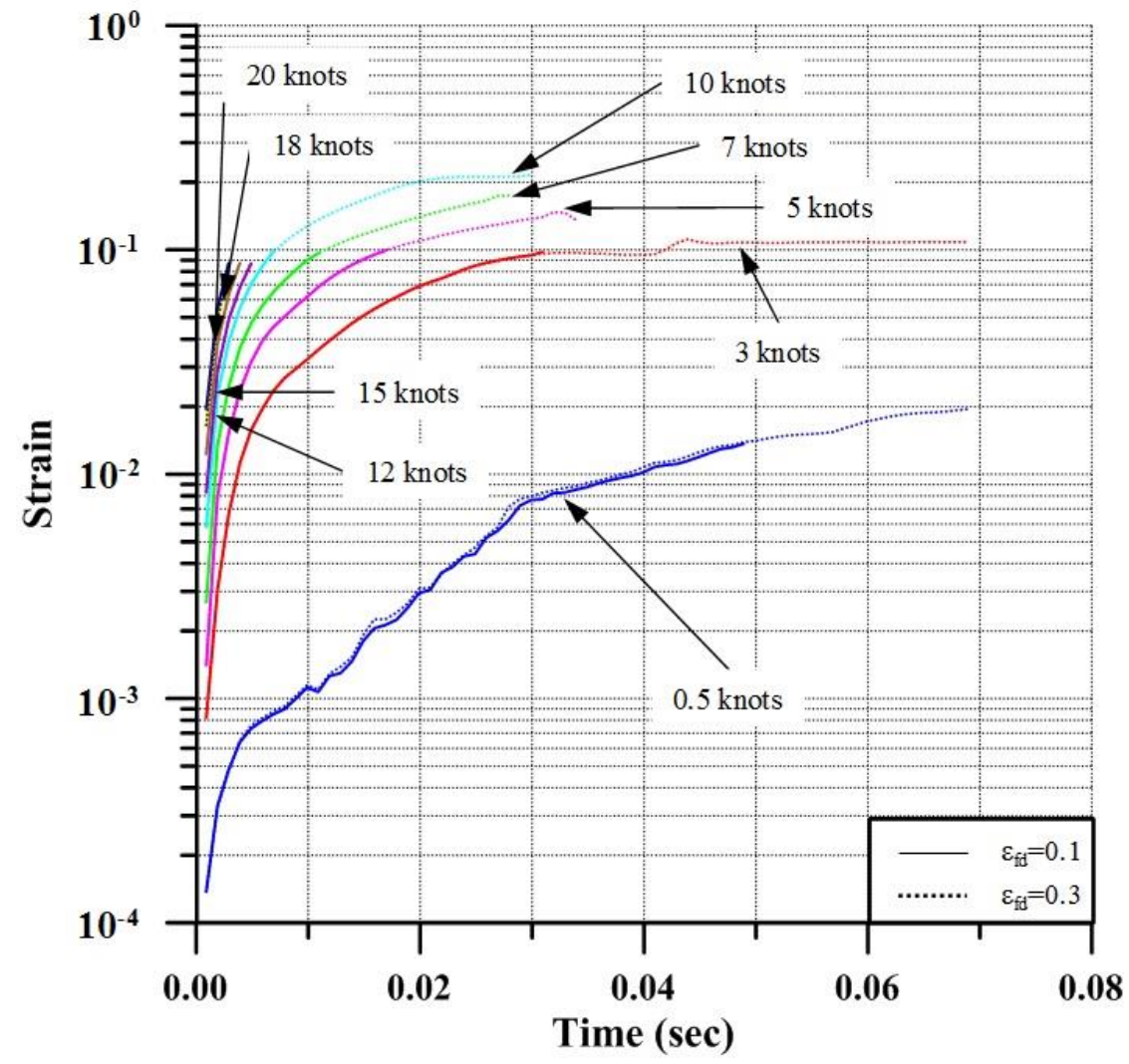

Figure 11. Computed results of strains with varying collision speed and dynamic fracture strain at the side shell of the struck ship. 


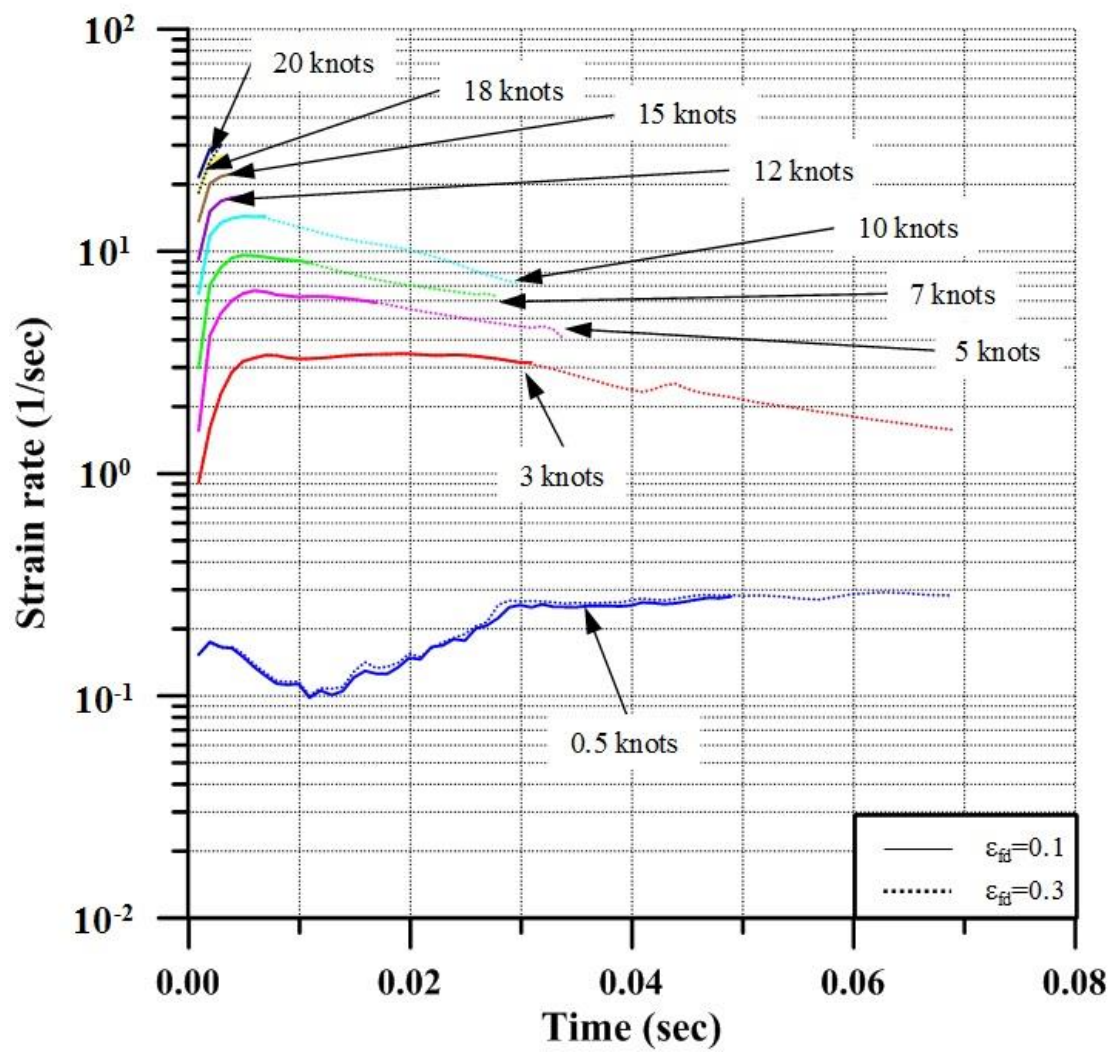

Figure 12. Computed results of strain rates with varying collision speed and dynamic fracture strain at the side shell of the struck ship.

3. An empirical formula to calculate the strain rate

Based on the computed results of maximum strain-rates indicated in Table 4, an empirical formula is now derived for calculating the strain rate $\dot{\varepsilon}$ as a function of the collision speed with the assumed dynamic fracture strain as follows:

$$
\dot{\varepsilon}= \begin{cases}1.528 V-0.685 & \text { for } \varepsilon_{f}=0.1 \\ 1.528 V-0.687 & \text { for } \varepsilon_{f}=0.3\end{cases}
$$

where $V$ is the collision speed in knot. Figure 13 shows the relationship between the maximum strainrate versus collision speed. It is found from Figure 13 that that the effect of the assumed dynamic fracture strain is negligible, and thus Equation (7) can be simplified as follows: 


$$
\begin{aligned}
& \dot{\varepsilon}=1.528 \mathrm{~V}-0.686 \text { for } V \text { in knot } \\
& \dot{\varepsilon}=2.97 \mathrm{~V}-0.686 \text { for } V \text { in } \mathrm{m} / \mathrm{s}
\end{aligned}
$$

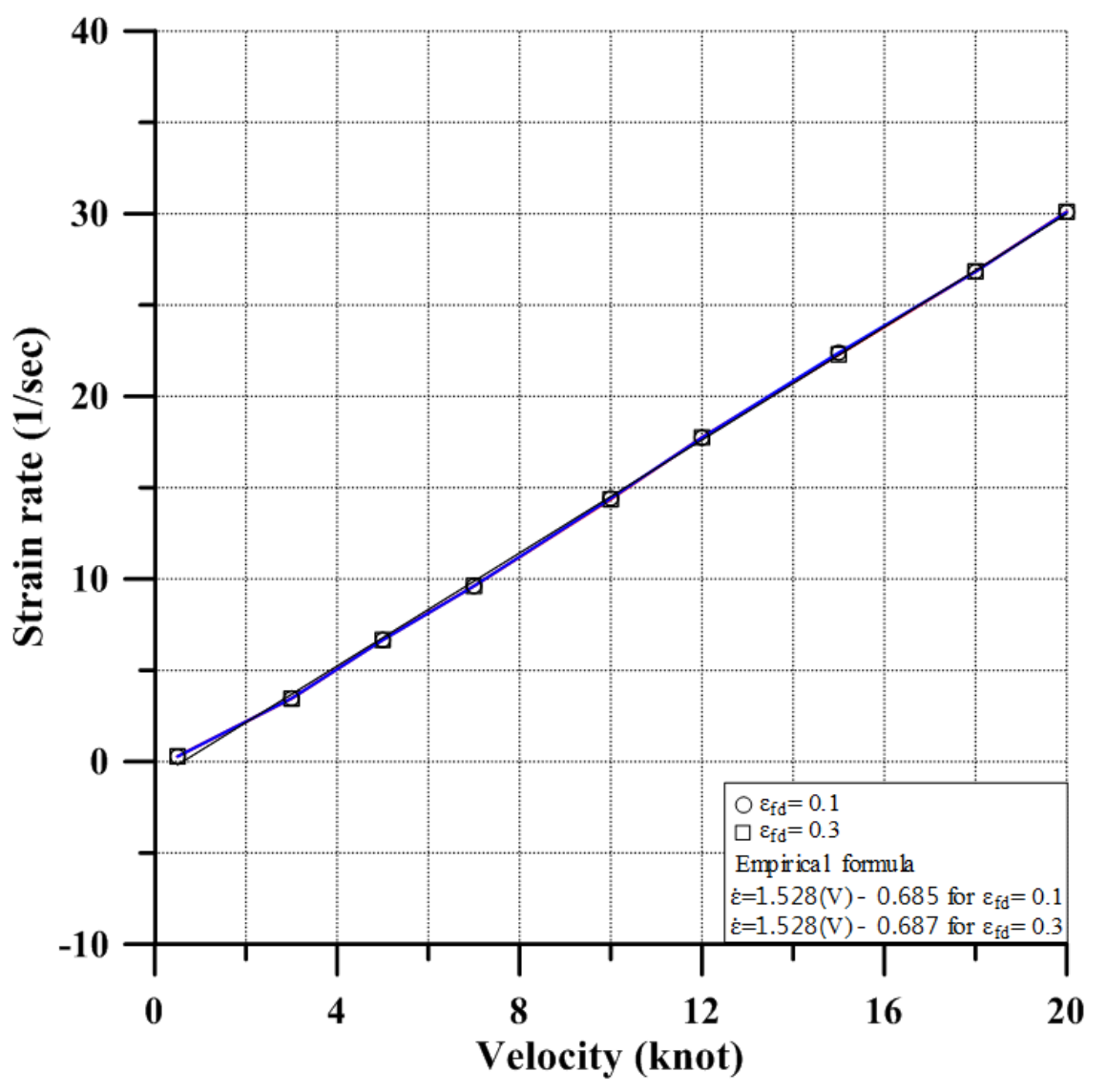

Figure 13. Relationship between the maximum strain-rate and the velocity of the striking ship with the assumed dynamic fracture strain.

4. Definition of the dynamic fracture strain

With the strain rate known as a function of the collision speed, the dynamic fracture strain can now be defined using the Cowper-Symonds equation. Figure 14 presents the flowchart to define the dynamic fracture strain to be used for the nonlinear FEA of structural crashworthiness in ship-ship collisions. 


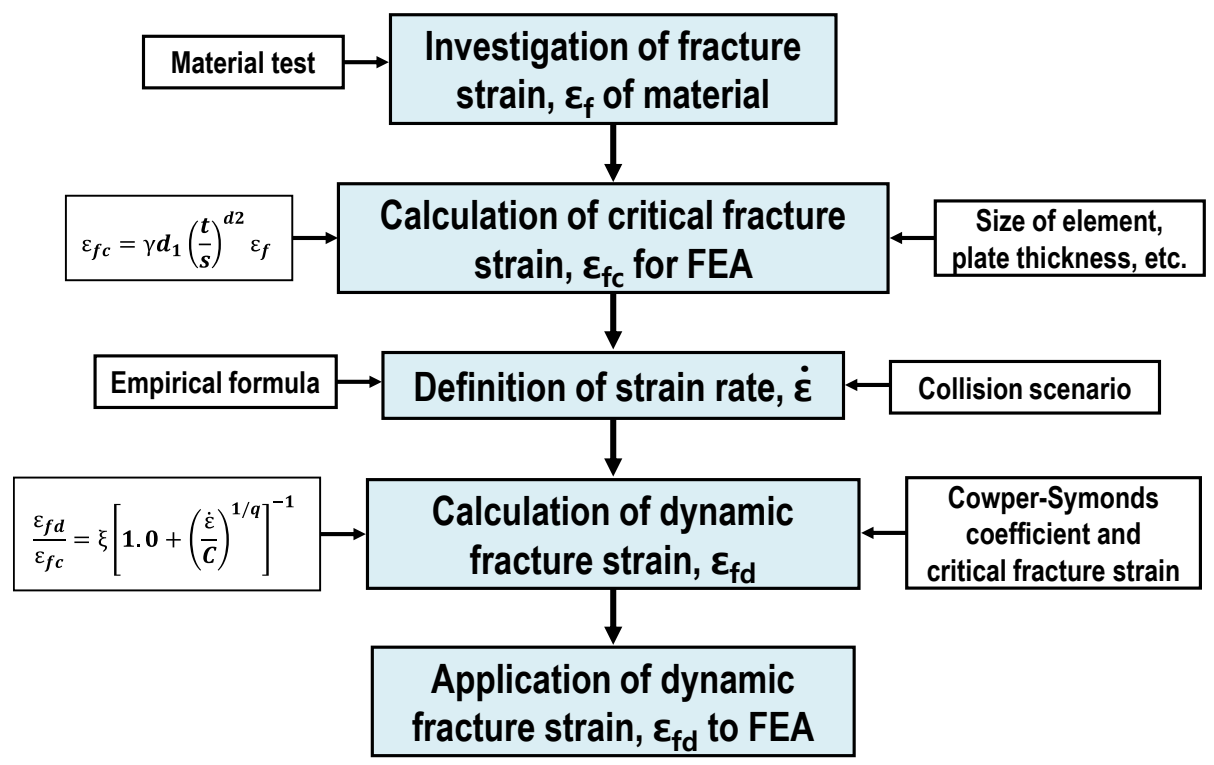

Figure 14. Flowchart for defining the dynamic fracture strain to be used for the nonlinear FEA.

Step 1. The static fracture strain $\varepsilon_{f}$ is defined from the tensile coupon test results or the nominal value of mechanical properties of material.

Step 2. The critical fracture strain $\varepsilon_{f c}$ to be used for the nonlinear FEA in the quasi-static loading condition is defined as a function of the finite element size and the plate thickness as follows (Hughes and Paik 2013):

$$
\varepsilon_{f c}=\gamma_{1} \gamma_{2} \varepsilon_{f}
$$

where $\varepsilon_{f}$ is the fracture strain obtained by the tensile coupon test, $\varepsilon_{f c}$ is the critical fracture strain, $\gamma_{1}$

is the factor associated with the mesh size and plate thickness that is defined as $\gamma_{1}=d_{1}\left(\frac{t}{s}\right)^{d_{2}}, t$ is the plate thickness, $s$ is the finite element size determined from Equation (4), $d_{1}$ and $d_{2}$ are the coefficients, and $\gamma_{2}$ is the correction or knock-down factor associated with localized bending due to folding. For carbon steel at room temperature, $d_{1}=4.1$ and $d_{2}=0.58$ may be used for $t=2 \mathrm{~mm}$. If $\gamma_{1}$ is smaller than 1.0 then $\gamma_{1}=1.0$ will be taken. With increase in the plate thickness, the 
localized bending effect becomes more significant, and thus the correction factor $\gamma_{2}$ takes a much smaller value than unity, such as $0.3-0.4$.

Step 3. The strain rate $\dot{\varepsilon}$ is defined as a function of collision (impact) speed from Equation (8).

Step 4. The dynamic fracture strain to be used for the nonlinear FEA can now be defined by an inverse of the Cowper-Symonds equation as follows (Paik et al. 2017b):

$$
\varepsilon_{f d}=\left[1+\left(\frac{\dot{\varepsilon}}{C}\right)^{1 / q}\right]^{-1} \varepsilon_{f c}
$$

where $\mathrm{C}$ and $\mathrm{q}$ are the Cowper-Symonds coefficients.

Table 5 indicates the dynamic fracture strains of the struck ship structures at the side shell of the struck ship, obtained from the procedure illustrated in Figure 14. In this computation, the static fracture strain $\varepsilon_{f}$ was taken as 0.43 for mild steel and 0.32 for high tensile steel which are obtained from the test database (Paik et al. 2017b). The coefficients in Equation (9) were taken as $d_{1}=4.1, d_{2}=0.58$ and $\gamma_{2}=0.3$. Also, the Cowper-Symonds coefficients $C$ and $q$ in Equation (10) are taken as indicated in Table 3.

Table 5. Applied examples of the dynamic fracture strain.

\begin{tabular}{|c|c|c|c|c|c|}
\hline \multirow{2}{*}{$\begin{array}{c}\text { Collision } \\
\text { velocity } \\
(\text { knot })\end{array}$} & $\begin{array}{c}\text { Strain rate } \\
(1 / \mathrm{sec})\end{array}$ & $\begin{array}{c}\text { Thickness of } \\
\text { the struck ship } \\
\text { side shell } t \\
(\mathrm{~mm})\end{array}$ & $\begin{array}{c}\text { Mesh size of the } \\
\text { struck ship side } \\
\text { shell } s \\
(\mathrm{~mm})\end{array}$ & \multicolumn{2}{|c|}{ Dynamic fracture strain } \\
\hline \hline 0.5 & 0.0785 & 14.5 & 191 & 0.092 & 0.079 \\
\hline 3.0 & 3.901 & 14.5 & 191 & 0.073 & 0.070 \\
\hline 5.0 & 6.959 & 14.5 & 191 & 0.070 & 0.068 \\
\hline 7.0 & 10.017 & 14.5 & 191 & 0.068 & 0.067 \\
\hline 10.0 & 14.604 & 14.5 & 191 & 0.065 & 0.066 \\
\hline 12.0 & 17.662 & 14.5 & 191 & 0.064 & 0.065 \\
\hline 15.0 & 22.249 & 14.5 & 191 & 0.063 & 0.064 \\
\hline 18.0 & 26.836 & 14.5 & 191 & 0.062 & 0.064 \\
\hline 20.0 & 29.894 & 14.5 & 191 & 0.061 & 0.063 \\
\hline
\end{tabular}


5. Validation of the proposed method

The proposed method is now validated by a comparison with experimental data. Although the strain rate formula developed in the present paper is based on the parametric studies of very large sized structures, it is interesting to confirm that the formula is applicable to small sized structures.

Liu et al. (2016) performed a dropped object test on a rectangular plate impacted by a rigid indenter as shown in Figure 15. The test plate is fixed at four edges. Table 6 indicates the material properties of the test plate. The test conditions are summarized as follows:

- Struck structure: flat rectangular plate with $1,000 \mathrm{~mm} \times 1,000 \mathrm{~mm} \times 4 \mathrm{~mm}$

- Striking object: cylindrical type with spherical head

- Edge condition: All (four) edges are fixed

- Weight of striking object: $1,350 \mathrm{~kg}$

- Drop height: $2 \mathrm{~m}$

- Initial velocity of striking object: $6.264 \mathrm{~m} / \mathrm{s}$

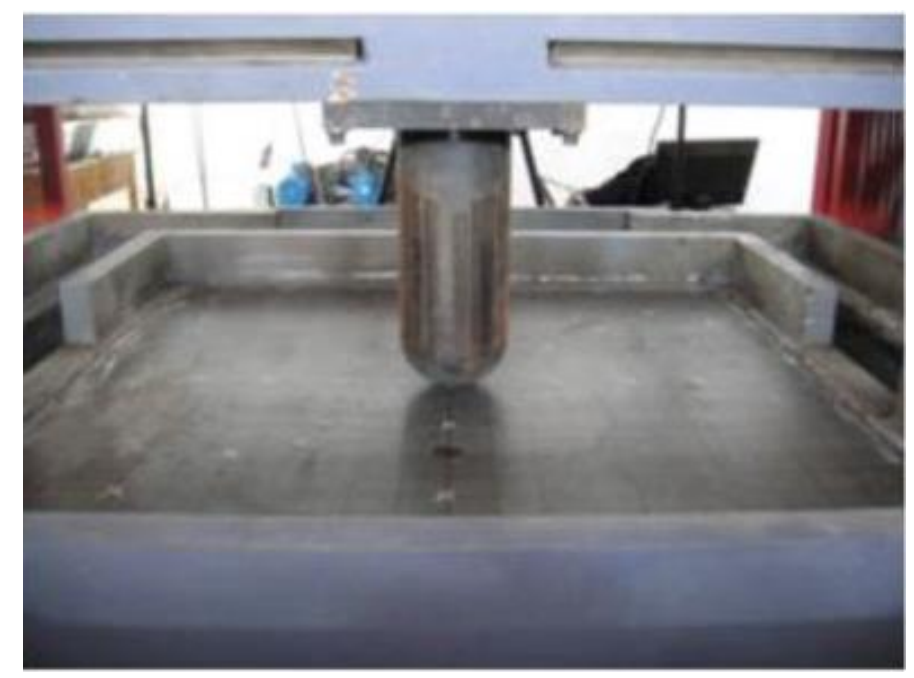

Figure 15. The dropped test on a rectangular plate impacted by a rigid indenter (Liu et al. 2016). 
Table 6. Mechanical properties of the struck plate in the dropped object test (Liu et al. 2016)

\begin{tabular}{|c|c|c|c|c|}
\hline Density & Young's modulus & Yield stress & Poisson's ratio & Fracture strain \\
\hline \hline $7,850 \mathrm{~kg} / \mathrm{m}^{3}$ & $201 \mathrm{GPa}$ & $245 \mathrm{MPa}$ & 0.28 & 0.31 \\
\hline
\end{tabular}

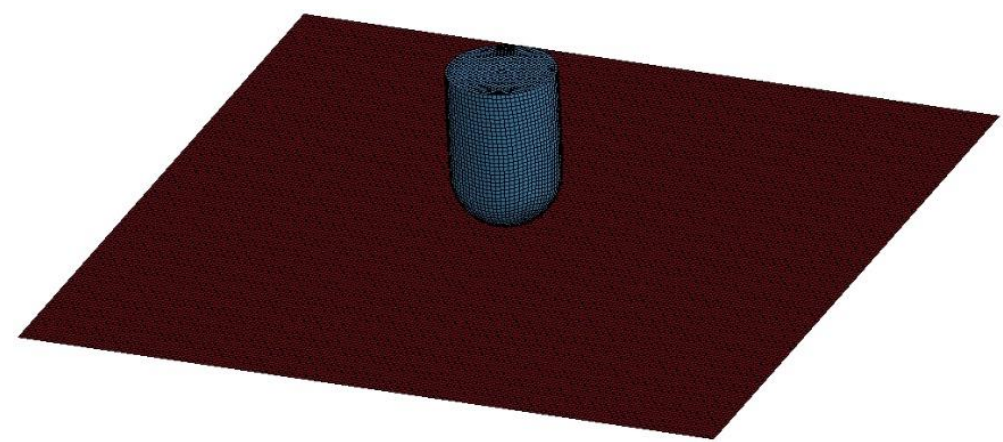

Figure 16. Nonlinear finite element method model of the test plate used in the present study.

Figure 16 shows the nonlinear finite element method model of the test plate using rectangular plate elements of $5 \mathrm{~mm} \times 5 \mathrm{~mm}$ where the size of meshes was decided by a convergence study (Liu et al. 2016). The all (four) edges are entirely fixed. The strain rate at the tip of the indenter is obtained from Equation (8) as 17.918/s because the initial impact velocity is $6.264 \mathrm{~m} / \mathrm{s}$. Also, the critical fracture strain to be used for the nonlinear FEA was determined from Equation (9) as 0.335 with the static fracture strain of 0.31 . The dynamic fracture strain $\varepsilon_{f d}$ to be used for the nonlinear FEA is now computed from Equation (10) as follows:

$$
\varepsilon_{f d}=\left[1+\left(\frac{\dot{\varepsilon}}{C}\right)^{1 / q}\right]^{-1} \varepsilon_{f c}=\left[1+\left(\frac{17.918}{40.4}\right)^{1 / 5}\right]^{-1} \times 0.335=0.181
$$

Figure 17 compares the present FEA with the experiment on the fracture of the test plate after testing. Figure 18 compares the reaction force-penetration relation. Figure 19 compares the absorbed energypenetration relation. It is observed that the results of the present FEA are in good agreement with the test results. 

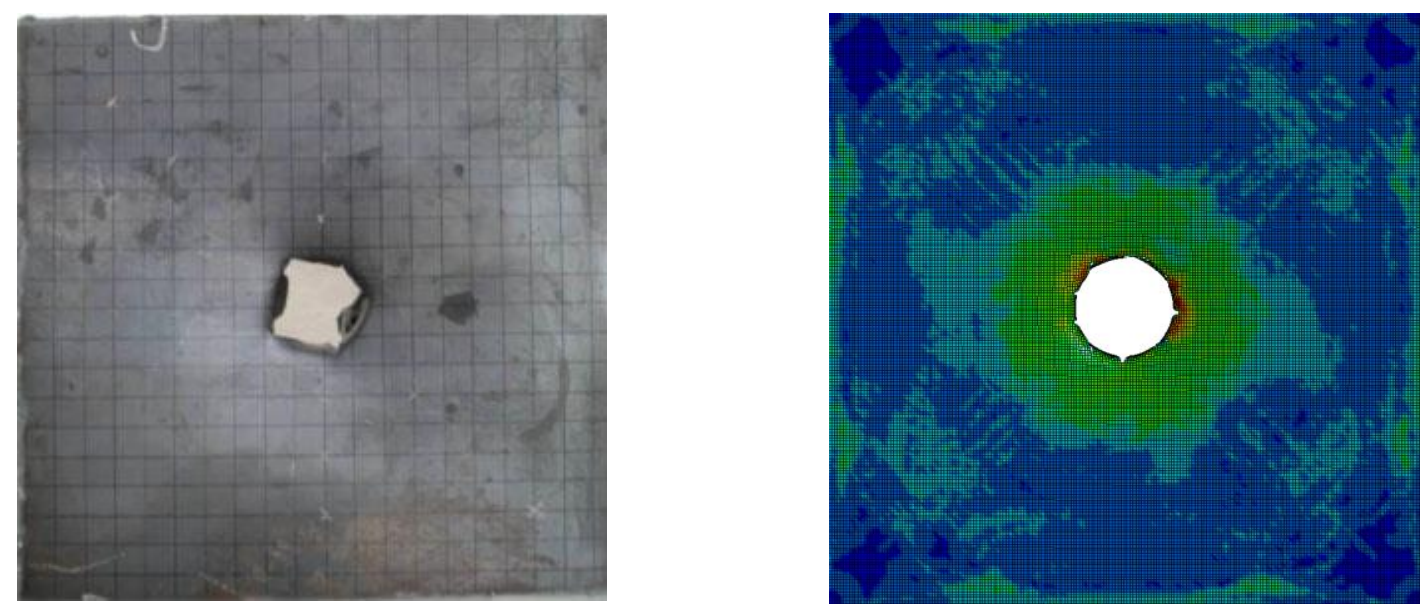

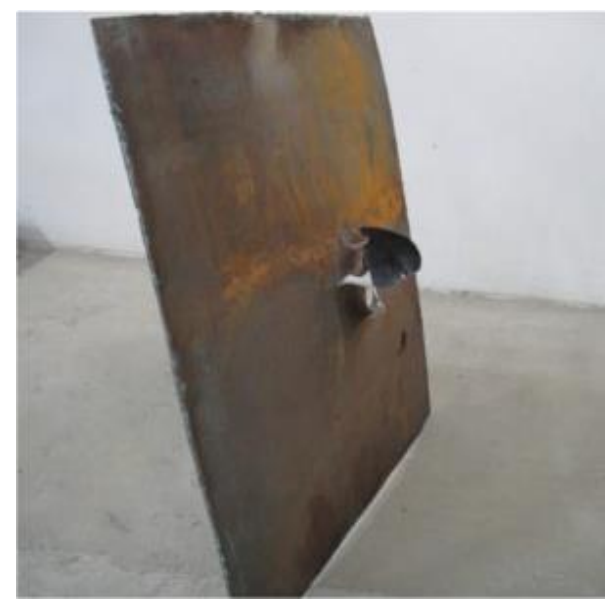

(a) Experiment

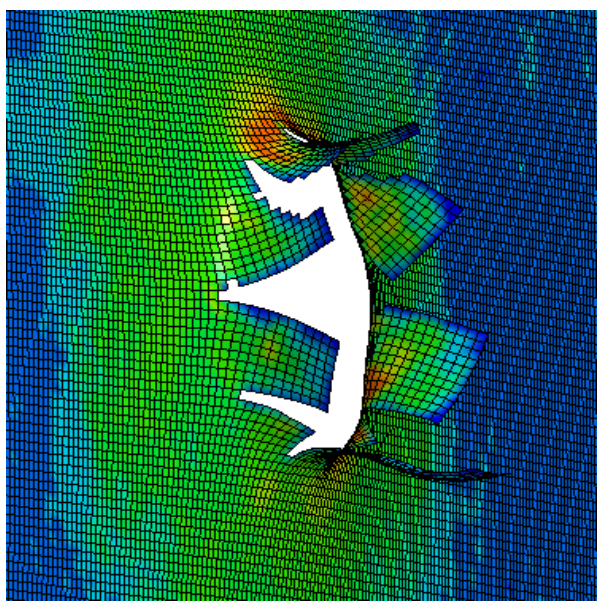

(b) Present FEA

Figure 17. Comparison of fracture of the struck plate after testing. 


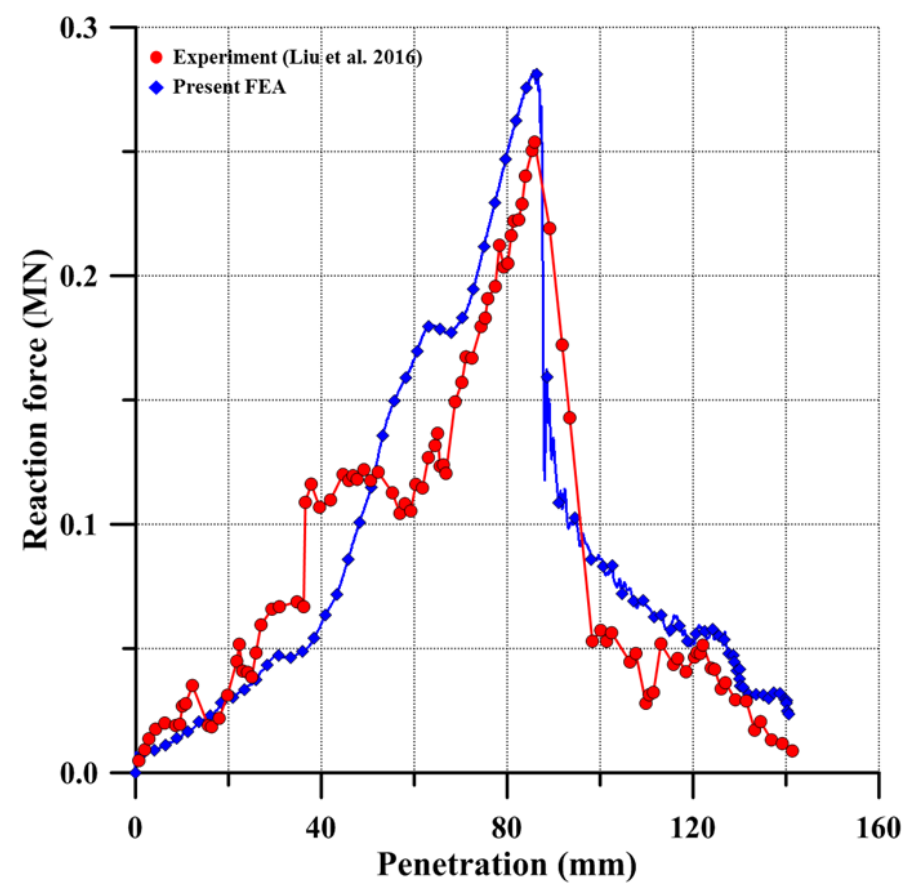

Figure 18. Comparison of the reaction force-penetration relation between the present FEA and the experiment.

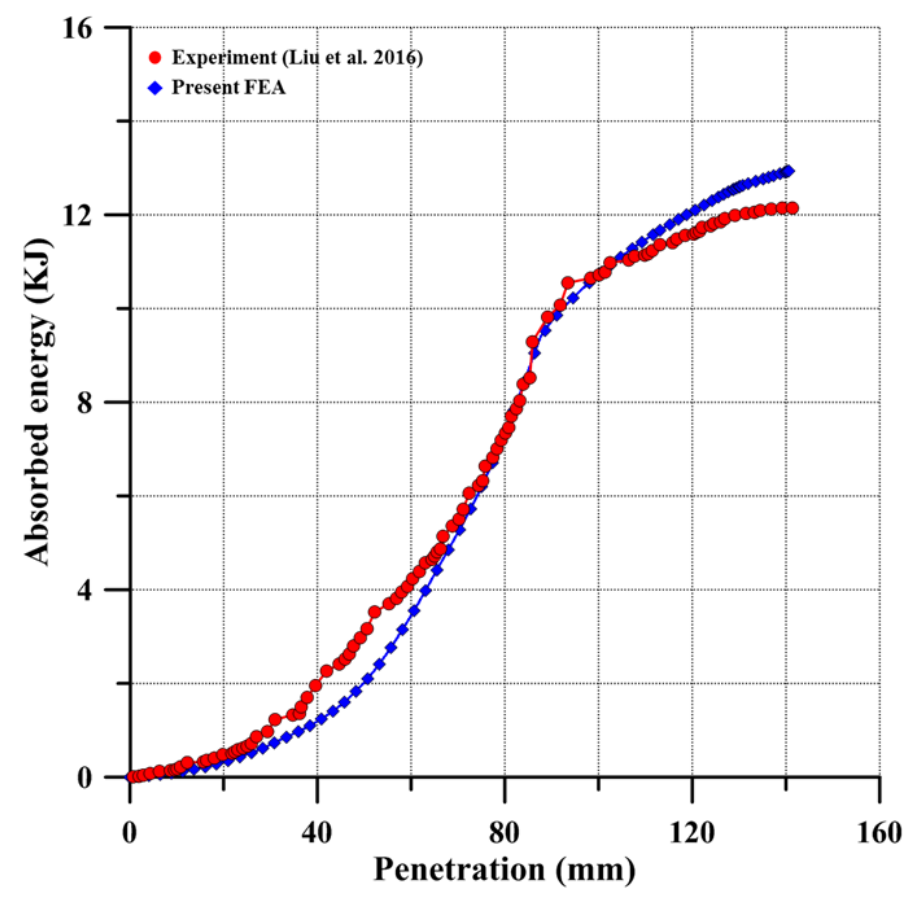

Figure 19. Comparison of the absorbed energy-penetration relation between the present FEA and the experiment. 


\section{Concluding remarks}

The objective of this study has been to propose a practical method to define the dynamic fracture strain to be used in the structural crashworthiness analysis of ship-ship collisions. For this purpose, an empirical formula was derived as a function of collision velocity to determine the strain rate based on the nonlinear finite element method computations with varying the collision velocity. The dynamic fracture strain was then determined from an inverse of the Cowper-Symonds equation. The proposed method was validated with experimental results, showing that it is useful to determine the dynamic fracture strain in nonlinear finite element method modeling for the structural crashworthiness analysis in association with ship-ship collisions.

Important findings and insights obtained from the present study are summarized as follows:

- The static fracture strain of material does not affect the maximum strain rate in ship-ship collision accidents.

- The strain rate in ship-ship collisions is almost linearly proportional to the collision speed.

- When the collision speed is relatively low, the strain rate in ship-ship collisions is reasonably close to the value of 0.1 , which is generally used in the current industry practice. However, the strain rate differs by about $34 \%$ for mild steel and $31 \%$ for high-tensile steel in high-speed collisions.

The use of the formula proposed in the present study would enable more accurate analysis and more realistic risk assessment in the event of ship-ship collisions. Also, the dynamic fracture strain obtained using the present formula could be used to improve safety design on the basis of ship speeds corresponding to the nominal continuous rating.

\section{Acknowledgements}

The present study was undertaken in the Korea Ship and Offshore Research Institute at Pusan National University which has been a Lloyd's Register Foundation Research Centre of Excellence. This 
work was supported by a 2-Year Research Grant of Pusan National University.

\section{References}

ANSYS/LS-DYNA, 2016. User's manual for ANSYS/LS-DYNA. Version 14.5, ANSYS Inc., New York, USA.

BV, 2013. Rules for the classification of offshore units. NR 455.D1 DT R04 E, Bureau Veritas, Paris, France.

Cowper GR, Symonds PS, 1957. Strain-hardening and strain-rate effects in the impact loading of cantilever beams. Technical Report No. 28, Division of Applied Mathematics, Brown University, Providence, RI, USA.

DNV, 2004. Rules for ships A300: collision and grounding. Det Norske Veritas, Olso, Norway.

Ehlers S, Guiard M, Kubiczek J, Hoderath A, Sander F, Sopper R, Charbonnier P, Marhem M, Darie I, Von Selle H, Peschmann J, Bendfeldt P, 2017. Experimental and numerical analysis of a membrane cargo containment system for liquefied natural gas. Ships and Offshore Structures, 12(S1): S257-S267.

Ehlers S, Tabri K, Romanoff J, Varsta P, 2012. Numerical and experimental investigation on the collision resistance of the X-core structure. Ships and Offshore Structures, 7(1): 21-29.

Faisal M, Noh SH, Kawsar M, Youssef SAM, Seo JK, Ha YC, Paik JK, 2016. Rapid hull collapse strength calculations of double hull oil tankers after collisions. Ships and Offshore Structures, 12(5): 624-639.

Ferry M, Le Sourne H, Besnier F, 2002. MCOL-Theoretical Manual. Technical Report 01-52, French Shipbuilding Research Institute, Nantes, France.

GL, 2011. Rules for classification and construction I: Ship technology. Germanischer Lloyd, Hamburg, Germany.

Haris S, Amdahl J, 2012a. An analytical model to assess a ship side during a collision. Ships and Offshore Structures, 7(4): 431-448. 
Haris S, Amdahl J, 2012b. Crushing resistance of a cruciform and its application to ship collision and grounding. Ships and Offshore Structures, 7(2): 185-195.

Hughes OF, Paik JK, 2013. Ship structural analysis and design. The Society of Naval Architectures and Marine Engineers, Alexandria, USA.

Jones N, 2006. Some recent developments in the dynamic inelastic behavior of structures. Ships and Offshore Structures, 1(1): 37-44.

Jones N, 2012. Structural impact. Second edition, Cambridge University Press, Cambridge, UK.

Khan IA, Das PK, 2008. Reliability analysis of intact and damaged ships considering combined vertical and horizontal bending moments. Ships and Offshore Structures, 3(4): 371-384.

Kim YS, Youssef SAM, Ince S, Kim SJ, Seo JK, Kim BJ, Ha YC, Paik JK, 2015. Environmental consequences associated with collisions involving double hull oil tankers. Ships and Offshore Structures, 10(5): 479-87.

Kitamura O, 2000. Buffer bow design for the improved safety of ships. Ship Structure Symposium, Virginia, USA, 13-14 June.

Ko YG, Kim SJ, Paik JK, 2017. Contribution of a deformable striking-ship structure to the structural crashworthiness of ship-ship collisions. Proceedings of International Conference on Ships and Offshore Structures, Shenzhen, China, 11-13 September.

Kuroiwa T, 1996. Numerical simulation of actual collision \& grounding accidents. Proceedings of International Conference on Design and Methodologies for Collision and Grounding Protection of Ships, San Francisco, USA, 22-23 August.

Kuroiwa T, Kawamoto Y, Kusuba S, Stillman D, 1995. Numerical Simulation of Collision and Grounding of Ships. Proceedings of the International Conference on Technologies for Marine Environment Preservation Tokyo, Japan, 24-29 September.

Le Source H, Couty N, Besnier F, Kammerer C, Legavre H, 2003. LS-DYNA applications in shipbuilding. Proceedings of the European LS-DYNA Users Conference, Ulm, Germany, 22-23 May. 
Liu B, Guedes Soares C, 2016. Assessment of the strength of double-hull oil tanker side structures in minor ship collision. Engineering Structures, 120: 1-12.

Liu K, Liu B, Guedes Soares C, Wang Z, 2016. Experimental and numerical analysis of a laterally impacted square steel plate. Proceedings of the International Conference on Maritime Technology and Engineering, Lisbon, Portugal, 4-6 July.

Obisesan A, Sriramula S, Harrigan J, 2016. A framework for reliability assessment of ship hull damage under ship bow impact. Ships and Offshore Structures, 11(7): 700-719.

Paik JK, 2007a. Practical techniques for finite element modeling to simulate structural crashworthiness in ship collisions and grounding (Part I: Theory), Ships and Offshore Structures, 2(1): 69-80.

Paik JK, 2007b. Practical techniques for finite element modeling to simulate structural crashworthiness in ship collisions and grounding (Part II: Validation), Ships and Offshore Structures, 2(1): 81-85.

Paik JK, Chung JY, 1999. A basic study on static and dynamic crushing behavior of a stiffened tube. KSAE Transactions, The Korea Society of Automobile Engineers, 7: 219-238 (In Korean).

Paik JK, Chung JY, Thayamballi AK, Pedersen PT, Wang G, 1999. On the rational design of double hull tanker structures against collision. Transactions of The Society of Naval Architects and Marine Engineers, 107: 323-363.

Paik JK, Kim SJ, Ko YG and Youssef SAM, 2017a. Collision risk assessment of a VLCC class tanker, The SNAME Maritime Convention, Houston, 23-28 October.

Paik JK, Kim KJ, Lee JH, Jung BG, Kim SJ, 2017b. Test database of the mechanical properties of mild, high-tensile and stainless steel and aluminium alloy associated with cold temperatures and strain rates. Ships and Offshore Structures, 12(S1): S230-S256.

Paik JK, Park JH, Samuelides E, 2009. Collision-accidental limit states performance of double-hull oil tanker structures: Pre-CSR versus CSR designs. Marine Technology, 46(4): 183-191.

Paik JK, Thayamballi AK, 2003. Ultimate limit state design of steel plated structures, Wiley, Chichester, UK. 
Paik JK, Thayamballi AK, 2007. Ship-shaped offshore installation: design, building and operation. Cambridge University Press, Cambridge, UK.

Sajdak JAW, Brown AJ, 2005. Modeling longitudinal damage in ship collisions. Report No. SSC-437, Ship Structural Committee, Washington DC, USA.

Samuelides MS, 2015. Recent advances and future trends in structural crashworthiness of ship structures subjected to impact loads. Ships and Offshore Structures, 10(5): 488-497.

Samuelides MS, Ventikos NP, Gemelos IC, 2009. Survey on grounding incidents: statistical analysis and risk assessment. Ships and Offshore Structures, 4(1): 55-68.

Servis DP, Samuelides MS, Louka T, Voudours G, 2002. The implementation of finite element codes for the simulation of ship-ship collisions. Journal of Ship Research, 46: 239-247.

Tabri K, 2012. Influence of coupling in the prediction of ship collision damage. Ships and Offshore Structures, 7(1): 47-54.

Tavakoli MT, Amdahl J, Leira BJ, 2012. Analytical and numerical modelling of oil spill from a side tank with collision damage. Ships and Offshore Structures, 7(1): 73-86.

Wierzbicki T, Abramowicz W, 1983. On the crushing mechanics of thin-walled structures. Journal of Applied Mechanics, 50: 727-734.

Youssef SAM, Faisal M, Seo JK, Kim BJ, Ha YC, Kim DK, Paik JK, Cheng F, Kim MS, 2016. Assessing the risk of ship hull collapse due to collision. Ships and Offshore Structures, 11(4): 335-350.

Youssef SAM, Ince ST, Kim YS, Paik JK, Cheng F, Kim MS, 2014. Quantitative risk assessment for collisions involving double hull oil tankers. International Journal of Maritime Engineering, 156(A2): 157-174.

Youssef SAM, Noh SH, Paik JK, 2017. A new method for assessing the safety of ships damaged by collisions. Ships and Offshore Structures, 12(6): 862-872.

Zhang S, Pedersen PT, 2017. A method for ship collision damage and energy absorption analysis and its validation. Ships and Offshore Structures, 12(1): 11-20. 
Zheng Y, Aksu S, Vassalos D, Tuzcu C, 2007. Study on side structure resistance to ship-ship collisions. Ships and Offshore Structures, 2(3): 273-293. 